Canadian

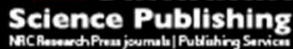

Canadian Geotechnical Journal Revue canadienne de géotechnique

\title{
Particle breakage in granular materials - a conceptual framework
}

\begin{tabular}{|r|l|}
\hline Journal: & Canadian Geotechnical Journal \\
\hline Manuscript ID & cgj-2017-0224.R1 \\
\hline Manuscript Type: & Article \\
\hline Date Submitted by the Author: & 12-Jul-2017 \\
\hline $\begin{array}{r}\text { Complete List of Authors: } \\
\text { Is the invited manuscript for } \\
\text { consideration in a Special } \\
\text { Issue? : }\end{array}$ & $\begin{array}{l}\text { Konrad, Jean-Marie; Université Laval, Civil engineering department } \\
\text { Salami, Younes; Université Laval, Civil engineering department }\end{array}$ \\
\hline Keyword: & $\begin{array}{l}\text { Particle breakage, Granular media, Grain crushing, Particle strength, Grain } \\
\text { size distribution }\end{array}$ \\
\hline \multicolumn{2}{|c}{} \\
\hline
\end{tabular}




\section{Particle breakage in granular materials - a conceptual 2 framework}

3 Jean-Marie Konrad ${ }^{1}$ and Younes Salami ${ }^{2}$

4 Département de génie civil et de génie des eaux, Université Laval

5 1065, avenue de la médecine, Université Laval, G1V 0A6, Québec (Québec), Canada

61. Email : jean-marie.konrad@gci.ulaval.ca

$7 \quad 2 . \quad$ Email : younes.salami@gci.ulaval.ca (Corresponding author) 
8 Abstract

9 A simple, yet complete framework is introduced with the aim of modelling grains breakage in

10 soils and crushable granular materials. The evolution of grain breakage is measured using a

11 specific parameter of the grain size distribution. The evolution of this new breakage parameter is

12 related to the applied mechanical work, which allows the predictions to be independent of the

13 stress paths. The correlation function proposed is tri-linear, and is capable of describing the

14 initiation, the development and the stabilisation of breakage. The initial state, coupled with three

15 additional parameters are used to calibrate this function. The three parameters are related to a

16 grain specific quantity representing the strength of the particles that form the granular medium.

17 The theory of fractal fragmentation is adopted, and the final state is considered to be unique, and

18 described by a single parameter: the fractal dimension. When tested against experimental results,

19 this model was able to correctly predict the crushable behavior of a sand.

20 Keywords : Particle breakage, granular media, grain crushing, fractal, particle strength, grain

21 size distribution

\section{Résumé}

23 Un cadre mécanique à la fois simple et complet est introduit dans le but de modéliser la rupture

24 des grains dans les sols et autres milieux granulaires broyables. L'évolution de la rupture des

25 grains est mesurée en utilisant un paramètre caractéristique de la distribution granulométrique.

26 L'évolution de ce nouveau paramètre de rupture est reliée au travail mécanique appliqué, ce qui

27 rend les prédictions indépendantes du chemin des contraintes. La fonction de corrélation proposée

28 est tri-linéaire, et donc capable de décrire l'initiation, le développement et la stabilisation de la

29 rupture. L'état initial, couplé à trois autres paramètres servent à calibrer cette fonction. Les trois

30 paramètres sont reliés à une quantité propre au grain, et qui représente la résistance des particules

31 qui forment le milieu granulaire. La théorie de la fragmentation fractale est adoptée, et l'état final 
32 est donc supposé comme étant unique, et décrit par un seul paramètre : la dimension fractale.

33 Lorsque le modèle est testé et les résultats comparés à des travaux expérimentaux, il devient 34 possible d'apprécier la capacité du modèle à simuler le comportement d'un sable. 


\section{Introduction}

36 Granular materials are of particular interest for civil engineers and soil mechanics specialists.

37 Over time, the integrity of these materials varies depending on the mechanical conditions, the

38 nature of the grain, and the structure of the granular packing. For example, significant particle

39 breakage is observed when the material is subjected to high stresses. The same amount of

40 crushing can develop for lower energies when the grains are weak. On the other hand, breakage is

41 more pronounced in a uniformly graded sample when compared to a well-graded sample. Hence,

42 a thorough understanding of the mechanics of these types of materials is essential in order to

43 optimize the lifetime of a structure and its aptitude for service.

44 When examining particle breakage, much of the attention has been concentrated on the plasticity

45 theories. Breakage is introduced as a hardening parameter (Daouadji et al. 2001; Einav 2007a;

46 Wood et al. 2009), or is calculated from the stress parameters that are computed independently

47 (Hu et al. 2011). In addition, breakage is considered to be a plasticity indicator, and starts with the

48 onset of plasticity, which does not represent the reality of the phenomenon. The development of

49 breakage continues indefinitely (with the loading). These approaches present the disadvantage of

50 neglecting important effects such as the strength of the particles, the initial grading, or the

51 stabilisation of the process. The main objective of this paper is to develop and validate a

52 conceptual model capable of relating the mechanical conditions to the corresponding amount of

53 grain breakage, based on representative parameters of the grains and the initial grading.

54 This research takes advantage of existing theories and experimental observations to propose a

55 simple mechanical model, able to estimate the development of grain breakage in a soil. The

56 method presented in this paper presents many advantages. It provides a simple way of relating the

57 strength of the particles to the parameters of a function that associates a breakage parameter to the

58 mechanical state. The proposed breakage parameter is capable of describing the evolution of the

59 soil's grading as a function of the imposed loading. This model can be useful for engineers that 
60 are looking for a simple technique to estimate breakage based on a basic knowledge of the soil

61 properties and the mechanical conditions.

\section{Background}

63 One of the most promising recent trends in soil mechanics has been the development and 64 application of multiscale techniques to study the mechanical behavior of soils. The grain level 65 properties and interactions become essential parameters in determining the macro-scale behavior.

66 For some problems where the effect of the microstructure is apparent, a multiscale approach is 67 not only interesting, but can become necessary for a complete analysis. For example, when 68 investigating grain crushing in granular materials, the breakage of a single grain is affected by 69 micromechanical conditions like the surrounding grains and the load carried by the force chain.

70 The fracturing of this grain goes on to affect the granular medium in a variety of ways (increased 71 compressibility, decreased peak shear strength ...).

72 In order to study this phenomenon from a constitutive point of view, multiple multi-scale 73 approaches have been proposed, each benefiting from one or more aspects of the effects of 74 breakage. Daouadji et al. (2001), who proposed one of the first constitutive models that consider 75 the effect of breakage, based their investigation on the effect grain breakage has on the critical 76 state line. This observation was the basis for many other constitutive models (Russell and Khalili 77 2002; Hu et al. 2011; Wood et al. 2009). The framework proposed by Einav (2007b) is based on a 78 yielding condition that derives from the definition of Einav's breakage parameter (Einav 2007b), 79 coupled to some other hypotheses.

80 When examining grain crushing and its effects on the behavior of a soil, two main issues have to 81 be addressed. The first issue deals with the definition of a variable capable of measuring the 82 extent of breakage, and the second concerns the ways to couple it to the mechanics of the 83 problem. The grading index chosen should be representative and relatable to the grain size 
84 distribution (GSD), while the mechanical correlation has to be stress path independent for a

85 complete description of the constitutive state of the material.

\section{Particle tensile strength}

87 When considering the failure of a mineral granular material under mechanical loading, it is 88 natural to assume that the nature and properties of the mother rock plays a determining role in 89 defining the strength of the particles. Many authors conducted crushing tests on rocks and rock

90 forming minerals, which allowed them to classify the minerals by order of resistance (Roy 1970;

91 Billam 1971). It is however, difficult to relate the strength of a rock aggregate to the strength of

92 the minerals that are part of its composition. Indeed, many microstructural parameters affect the

93 fracturing of a grain, like the distribution of the micro-cracks and voids, the size of the minerals,

94 their distribution, their size and exact nature. The effect of other mineralogical aspects like the

95 type of bonds between the minerals, the degree of metamorphism and other development and

96 alteration conditions greatly affect the mechanical behavior of the rock particle, and can be

97 problematic to study and model.

98 One simple way of examining the failure of a rock particle is through simple tests that determine

99 the tensile strength of the grain. By doing so, we consider that the dominant breakage mode is the

100 opening tensile fracture mode. The two shearing fracture modes (II and III) that are responsible

101 for the production of fines through attrition and abrasion are consequently neglected. The tensile

102 strength of a grain is usually measured by Brazilian type techniques like the point load test, or the

103 diametric compression under two parallel platens. For these types of tests, the tensile strength is

104 related to the critical force at failure $F_{C}$ by (Jaeger 1967):

$$
\sigma_{c}=\frac{F_{c}}{d^{2}}
$$

105 where $d$ is a characteristic size of the rock particle. On a force-displacement plot (figure 1), the 106 first peaks are usually caused by the crushing of angular contacts or asperities, or by spalling, and 
107 are usually neglected. The critical force is measured when the particle effectively splits into two 108 or a number of fragments with comparable sizes. On figure 1, this corresponds to diametral 109 breakage at a critical load of $2.7 \mathrm{kN}$.

110 Figure 2 is a compilation of the tensile strength of multiple particles of various sizes. The data 111 was compiled by Soga (2005) after the experimental results of Lee (1991), McDowell and Amon 112 (2000) and Nakata et al. (2001). The figure shows that for the same material, larger particles tend 113 to be weaker, while smaller ones are stronger. This is because the larger particles contain more 114 micro cracks and voids, which allows the particles to break more easily.

115 It should be noted that the breakage of a rock aggregate is affected by multiple factors. The form 116 of the grain can be cited as an example, where important geometrical aspects like the sphericity, 117 roundness and surface texture determine the failure behavior of the grain, and the characteristics 118 of the fragments (Cavarretta 2009). For instance, a $1 \mathrm{~mm}$ diameter angular glass particle displays 119 a tensile strength of about $60 \mathrm{MPa}$ while a rounded glass particle has a tensile strength of 220 $120 \mathrm{MPa}$, i.e., almost 4 times greater (figure 2). This is due to the smaller contact area in angular 121 grains compared to rounded grain, which amplifies the concentration of forces near the contacts, 122 and results in a decreased strength (Salami et al. 2017). Other important aspects that should be 123 considered when researching the fracture mechanics of mineral granular aggregates are the 124 coordination number, the contact dynamics and the presence of corrosive elements (water was 125 shown to accelerate the development of a crack (Atkinson 1987)).

\section{Evolution of GSD by particle breakage}

127 One of the main challenges that arise when considering grain breakage from the packing level is 128 to correctly quantify the amount of particle breakage that occurs in the granular medium. Many 129 authors proposed multiple measures of grain breakage that are generally related to the evolution 130 of the grain size distribution (GSD) (Lee and Farhoomand 1967; Marsal 1973; Hardin 1985; 
131 Einav 2007b). These breakage parameters can then be correlated with mechanical and/or 132 hydraulic parameters through empirical formulas, which would allow modelling of the behavior 133 of soils at extreme conditions, or during extended periods of time.

134 One simple way to measure the extent of breakage in a soil is to examine the evolution of one of 135 the form factors of the GSD (the most representative example being the coefficient of uniformity $136 C_{u}$ (Colliat-Dangus et al. 1988)). The slope of the linear evolution of the GSD in a log-log plot 137 was found to be reasonably representative of this evolution (log refers to the decimal logarithm). 138 Figure 3 is a plot of the evolution of GSD from its initial to an ultimate GSD for an assemblage of 139 gneissic particles subjected to oedometric compression. The classical semi-logarithmic plot of 140 figure 3-a can be transformed to the log-log plot of figure 3-b, where it is reasonable to consider 141 that the GSDs are well represented by a linear function, particularly towards the ultimate state. 142 Assuming knowledge of the largest size fraction $d_{100}$ of the granular packing, the slope of the 143 linear GSDs in the log-log scale is sufficient to fully characterize the GSD by its slope $v$.

144 It should be noted that $v$ suffers the same limitations as other breakage parameters in the sense 145 that a single parameter cannot fully describe the GSD. Marsal's (1967) index cannot be related to 146 a granular distribution, while Hardin's (1985) parameter limits the changes in the GSD to the 147 higher size fraction by stating that the sizes lower than $0.074 \mathrm{~mm}$ do not contribute to breakage. 148 Many other shape parameters for the GSD ignore certain size fractions (the coefficient of 149 uniformity, crushing coefficient, Lee and Farhoomand (1967) parameter ...). Other parameters 150 are fundamentally related to a constitutive framework, and would be difficult to adapt to this 151 study (Einav (2007b); Kikumoto et al. (2010) ...). The linear approximation in the logarithmic 152 space offers an acceptable description of the GSD without ignoring any size fraction.

153 The constitutive models that consider the effect of grain breakage generally adopt a hardening 154 rule that relates a breakage parameter to a stress variable, generally the mean effective stress $p$ or 155 the pre-consolidation stress $p_{c}$ (McDowell et al. 2002; Einav 2007a; Kikumoto et al. 2010). This 
156 provides a straightforward way to include the effect of breakage through a single mechanical 157 parameter. Since most of these models borrow some aspects of the critical state theory and 158 because the effects of grain breakage on the critical state behavior are well documented (Biarez 159 and Hicher 1994), the stress parameter $p$ is usually a good candidate for a mechanical correlating 160 parameter from a constitutive view. It was however shown that the breakage variable cannot be 161 related to a single stress parameter for all stress paths. The experimental results of Roy (1970) on

162 Quebec limestone (figure 4) show that a considerable amount of grain breakage occurs along the 163 triaxial paths, as confirmed by the important changes in the uniformity coefficient (in the order of $16470 \%$ when $p$ reaches $12 \mathrm{MPa}$ ). The relatively smaller changes in the uniformity coefficient (less 165 than 10\%) for that same stress when a comparable specimen is subjected to isotropic 166 consolidation confirm that a single stress parameter, in this case the mean effective stress, does 167 not correlate well enough with the breakage parameter.

168 In order to couple the mechanical aspects of the soil's behavior with the evolution of grain 169 breakage, many authors proposed a correlation between the amount of breakage and a quantity 170 representing some form of energy input, transformation or dissipation. Miura and O-Hara (1979), 171 who used the surface area as a breakage parameter, established an increasing relationship between 172 the plastic work and the increase of surface area. The function that relates the two parameters was 173 shown to be an ' $S$ ' type curve, meaning that breakage begins developing at the earliest stages of 174 the loading, before increasing in rate for the intermediate energies, and then decreasing for the 175 higher energies. The ' $S$ ' function exhibits the typical behavior for the development of breakage 176 observed in a crushable granular material, which can be described in three stages:

177 - An early stage, where the development of grain breakage is negligible;

178 - An intermediate stage, where the rate of development of grain breakage is at the 179 maximum. The concavity of the ' $S$ ' function in this region is subject to much debate, and 
the modelling of this evolution takes many forms (see later for a detailed discussion on the importance of a good description of this region for constitutive models).

- A final stage, where grain breakage tends to stabilize. This is consistent with observations of the fragmentation processes in general, that state that the function (size the fragment number of fragments in this size fraction) converges towards a unique, self-similar distribution.

This three-stage behavior was later confirmed by many authors (Biarez and Hicher 1994; Lade et important to note that even though this behavior might look similar to the compressibility curve of a soil (volume-pressure relationship), they represent different concepts that are difficult to

190 relate. The initiation of breakage and its stabilisation are not the result of the first and second 191 inflexions of the compressibility curve (the transition to the normal compression line, and to the 192 critical state line).

193 Lade et al. (1996) proposed correlating Hardin's (1985) breakage parameter to the total energy 194 input instead of the plastic energy as suggested by Miura and O-Hara. This was justified by the 195 fact that very little elastic energy develops in a specimen with crushable particles. They proposed 196 a simple way of calculating the total work input, which is then used to calculate the energy input 197 for multiple tests on Cambria sand compiled from the literature. The total energy and Hardin's 198 breakage parameter are related through a single hyperbolic function, which is similar to the ' $\mathrm{S}$ ' 199 function described earlier (a stage where breakage develops rapidly followed by a relative 200 stabilisation of breakage).

201 The results of Roy, which were used to show that the stress parameter $p$ did not correlate well 202 with a breakage parameter (see figure 4) are revaluated in light of the findings of Lade et al. 203 (1996). The work input was calculated from the stress-strain curves using the formula proposed 
204 by Lade et al. (Op.Cit.). Figure 5 shows that the work per unit volume correlates well with the 205 coefficient of uniformity (i.e. the evolution of GSD) independently of stress path.

\section{Conceptual framework for the prediction of particle breakage in granular materials}

207 The characteristic behavior described in the previous paragraph is used here as a reference for 208 defining a conceptual framework able to describe and predict the evolution of breakage, 209 independent of the stress path. This is achieved by correlating the breakage parameter (in this 210 case $v$, the slope of the GSD in the log-log space) to the input work per unit volume. The work

211 per unit volume is calculated using eqn 2, similar to that proposed by Lade et al. (1996):

$$
\frac{W}{V}=\sum_{0}^{f}\left(\sigma_{c} \dot{\varepsilon_{v}}\right)+\sum_{0}^{f}\left(\sigma_{1}-\sigma_{3}\right) \dot{\varepsilon_{a}}
$$

212 where $\mathrm{W}$ represents the total work, $V$ the volume of the element considered, $\sigma_{c}$ the confining

213 pressure, $\left(\sigma_{1}-\sigma_{3}\right)$ the deviatoric stress, $\dot{\varepsilon_{v}}$ the increment of volumetric strain, and $\dot{\varepsilon_{a}}$ the

214 increment of axial strain. The summation is applied between an initial state 0 and a final state $f$.

215 According to the behaviour of crushed limestone (Lo and Roy 1973), the evolution of breakage in

216 any granular material can be approximated by three distinct phases in a $\log v-\log \left(\frac{W}{V}\right)$ space as

217 illustrated by Figure 6 describing the initiation, development and stabilization of grain breakage

218 as a function of input work. For a given material characterized by an initial GSD, $v_{i}$, negligible

219 grain breakage will occur in the first phase from A to B until the input work reaches a critical

220 value $W_{\text {crit }}$ i.e. at the initiation of grain breakage. When the work applied exceeds $W_{\text {crit }}, v$

221 decreases with increasing work increments. In phase 2 where significant grain breakage occurs,

222 the representative point moves from B to C. During phase 2, the GSD is increasingly spread out

223 over the finer fractions, since breakage causes larger particles to crush into smaller ones. At Point

$224 \mathrm{C}$, the intensity of breakage will stabilize and the GSD reaches an ultimate distribution 
225 characterized by the parameter $v_{u}$. It is assumed that any work increment larger than $W_{\text {crit }}$ will 226 not produce further grain breakage (path CD).

227 In order to characterize the evolution of $v$ as a function of the applied work, four parameters are 228 required (Figure 7):

$229 \quad-\quad v_{i}$ : which represents the slope of the initial GSD in a log-log plane; - $\quad v_{\text {ref }}:$ a reference value of $v$ at a reference value of $\frac{W_{r e f}}{V}=0.01 M P a$;

- $\quad \alpha$ : the slope of segment BC;

- $\quad v_{u}$ : the ultimate GSD. When $v$ reaches this ultimate value, a stabilisation of crushing is

234 The conceptual model applies for any GSD, which satisfies the condition $v_{\mathrm{i}}<v_{\text {ref }}$ and can be 235 described by the following equations:

$$
\begin{gathered}
W<W_{\text {crit }} \quad v=v_{i} \\
W \geq W_{\text {crit }} \quad \log \left(\frac{v}{v_{i}}\right)=-\alpha \log \left(\frac{W}{W_{\text {crit }}}\right) \\
W_{\text {crit }}=0.01\left(v_{\text {ref }} / v_{i}\right)^{\frac{1}{\alpha}} \quad(M P a)
\end{gathered}
$$

236 The parameters $v_{r e f}$ and $\alpha$ depend on the micromechanical and mineralogical properties of the 237 granular material. The parameter $v_{u}$ can be related to the fractal dimension of the material and 238 will be discussed in more details below.

239 In order to establish a correlation between $v_{\text {ref }}$ and $\alpha$, and a parameter representing the nature of 240 the rock, an extensive study has been conducted based on published results on the breakable 241 behavior of several granular materials. Since it has been shown that the tensile strength of the 242 rock aggregate is a good indicator of the influence of the nature of the rock on the mechanical 243 behavior of the granular packing, the strength of the size fraction $d_{50}$ (the size corresponding to $24450 \%$ passing by mass) was considered as a representative parameter of the mineralogy of the 
245 rock. The values of $v_{r e f}$ and $\alpha$ corresponding to each of the materials analysed herein were

246 determined based on the experimental data and plotted against the tensile strength of the grain

247 size fraction $d_{50}$ (figure 8). The data were compiled from various sources $\left(\mathrm{Al}_{2} \mathrm{O}_{3}\right.$, Quartz, and

248 crushed limestone from Roy (1970), Kenamu sand from (Leclerc 1998), Ottawa sand from

249 (Hagerty et al. 1993), carbonate sand from (Coop et al. 2004) and Cambria sand from (Yamamuro

250 and Lade 1993). The data for Romaine granite were obtained from an experimental investigation

251 conducted for this study. Additional tensile strength tests were also conducted on $\mathrm{Al}_{2} \mathrm{O}_{3}$ particles

252 and added to the data on figure 2.

253 It is clear from figure 8 that both $v_{r e f}$ and $\alpha$ can be approximated by a logarithmic function when

254 these parameters are related to the tensile strength of the average particle size $d_{50}$. This function

255 is decreasing in the case of parameter $\alpha$ and increasing for parameter $v_{r e f}$. The best fit trend lines

256 yield two empirical formulas given by eqn 4 that allow the calculation of parameters $v_{r e f}$ and $\alpha$

257 based on the tensile strength of the particle $d_{50}$, which is noted $\overline{\sigma_{t}}$ :

$$
\begin{gathered}
\alpha=-0.061 \ln \left(\overline{\sigma_{t}} / \overline{\sigma_{r e f}}\right)+0.65 \\
v_{r e f}=2.061 \ln \left(\overline{\sigma_{t}} / \overline{\sigma_{r e f}}\right)+2.17
\end{gathered}
$$

258 The $\ln$ refers to the natural logarithm. $\overline{\sigma_{r e f}}$ is introduced for the purpose of homogeneity, and is 259 considered to be equal to $1 \mathrm{MPa}$. The third parameter of the model, $v_{u}$, will be discussed in more 260 details below. Many other parameters like the evolution of particle shape are neglected by 261 equations (4), which might explain the scatter from the logarithmic trend lines.

\section{Prediction of the evolution of the GSD and fine content}

263 The capabilities of this new conceptual model are tested through the simulation and prediction of 264 the coupled mechanical-crushable behavior of Hostun sand $\left(\mathrm{d}_{\max }=0.37 \mathrm{~mm}, \mathrm{~d}_{10}=0,21 \mathrm{~mm}, 10 \%\right.$

265 finer than $\mathrm{d}_{10}$ ) subjected to various stress paths (Colliat-Dangus 1986; Colliat-Dangus et al. 1988).

266 The objective of this analysis is to estimate the extent of breakage in a given soil based on the 
267 mechanical conditions and the particle's properties inferred from the relationships presented in 268 figure 8 . The experimental data reported by Colliat-Dangus (1986) comprised five isotropic 269 compression tests on loose and dense samples, two oedometric compression tests on a dense 270 sample, and seven triaxial compression tests on dense samples. The data for Hostun sand are 271 summarized in figure 9. Figure 9a shows the results of the isotropic consolidation tests for loose 272 and dense samples, figure $9 \mathrm{~b}$ presents the compressibility curves for two oedometric tests on 273 dense sand samples and figure 9c illustrates the stress-strain response of drained triaxial 274 compression tests. No other data on the evolutions of the GSDs, besides the initial GSD (the 275 same for all the tests), was provided but the amount of crushing was measured in terms of a 276 crushing coefficient introduced by the authors. The crushing coefficient $C_{c}$ was defined as the 277 fraction finer than the characteristic size $d_{10}$ associated with the initial GSD, in a cumulative 278 distribution by mass, divided by 10 :

$$
C_{c}=\frac{\% \text { finer than the initial } d_{10}}{10}
$$

279 The evolution of the crushing coefficient for all the tests analysed herein is presented in figure 10.

280 The parameter $v$ is calculated using the formula:

$$
v=\frac{\log (100)-\log \left(10 C_{c}\right)}{\log (0.37)-\log (0.21)}
$$

281 The stress-strain curves of figure 9 are used to calculate the mechanical work using the formula 282 (2).

283 In order to define the parameters of the model, the strength of a particle with a size corresponding 284 to $d_{50}$ is obtained from figure 2 for a characteristic size associated with $50 \%$ passing by size, i.e., $2850.4 \mathrm{~mm}$ considering a quartz particle which yields a corresponding strength of 120MPa. 286 Equations (4) provide the values of $\alpha=0.34$ and $v_{r e f}=12.07$ which, in turn, gives the 287 conceptual breakage characteristics shown in figure 11 in the $\left(\log v-\log \frac{W}{V}\right)$ space. 
288 The initial grain size distribution yields an initial value of $v$ equal to $v_{i}=4.065$ and gives a value 289 of the critical work for the initiation of breakage of $0.25 \mathrm{MPa}$ according to eqns (3).

290 Figure 11 is a plot of the experimental data for all the tests considered compared to the proposed 291 model summarized by eqns (3) and (4). A good agreement is achieved between the experimental 292 and predicted results.

293 This model, which is based on the work as a measure of the mechanical state, has the advantage 294 of providing a single mechanical-crushable correlation for all stress paths.

\section{Ultimate grain characteristics}

296 When a granular material is subjected to extremely high stress conditions, the grain size 297 distribution becomes self-similar, and can be correctly estimated by a fractal distribution. This 298 means that the fragmentation process become scale invariant. Turcotte (1997) gathered the results 299 of many experimental studies of the frequency-size distribution of mineral fragments resulting 300 from high impact events like explosions or projectile impacts. He was able to correctly approach 301 the grain size-frequency distribution by the fractal power relation:

$$
N(d)=f\left(d^{-D}\right)
$$

$302 N(d)=$ the number of fragments of size $d$, and $D=$ the fractal dimension of the distribution. It 303 was shown that the fractal dimension for granular mineral materials has a value of about 2,5 . This 304 relation can then be used to relate the cumulative distribution by mass $F(d)$ for a size fraction, to 305 the characteristic size of this fraction $d$, the size of the biggest grain in the distribution $d_{M}$, and 306 the fractal dimension $D$ (Turcotte 1986):

$$
F(d)=\left(\frac{d}{d_{M}}\right)^{3-D}
$$


307 Alternatively, when the fractal distribution is reached, the parameter $v$ is equal to its ultimate 308 value $v_{u}$. The passing fraction by mass for a size fraction $F(d)$ is by definition, related to the 309 parameter $v_{u}$ by the relation:

$$
\log (F(d))=v_{u} \log \left(\frac{d}{d_{M}}\right)
$$

310 From the two expressions (8) and (9), the parameter $v_{u}$ can be related to the fractal dimension $D$

311 by: $v_{u}=3-D$. Rather than using the conventional fractal dimension $\mathrm{D}$, it is proposed herein to

312 use the breakage parameter $v_{u}$. In figure 12, the value of $v$ at its ultimate state or near it, $v_{u}$, has

313 been plotted against the particle strength for several materials of different mineralogy and

314 different sizes. Similarly to parameters $\alpha$ and $v_{\text {ref, }}$ a unique relationship can be established

315 between $v_{u}$ and the average particle strength, $\bar{\sigma}_{t}$, independently of mineralogy:

$$
v_{u}=0.190 \ln \left(\overline{\sigma_{t}} / \overline{\sigma_{r e f}}\right)-0.14
$$

316 It should be noted that it is quite difficult to experimentally reach a fractal distribution.

317 Sometimes, a partial stabilisation of the process of breakage results in the faulty assumption that

318 the fractal state is attained, which can lead to an underestimation of the fractal dimensions. This

319 might explain the scatter observed in figure 12.

320 A working example: Marsal's experiments on Granitic Gneiss

321 Marsal (1967) was probably one of the first to perform large-scale triaxial tests on rockfill 322 materials (the cylindrical specimen was $113 \mathrm{~cm}$ in diameter and $250 \mathrm{~cm}$ in height). The material 323 used in his study was composed of granitic gneiss particles resulting from quarry blasts. Out of 324 the two gradations considered in the original work, the well-graded distribution is considered, 325 where the biggest grain had a characteristic dimension of $200 \mathrm{~mm}$, while the dimension 326 corresponding to a $10 \%$ passing was $4 \mathrm{~mm}$ and the mean particle size was $60 \mathrm{~mm}$. According to 327 figure 2 and from strength data reported by Marsal, the strength of a $60 \mathrm{~mm}$ particle is about 
$328 \bar{\sigma}_{t}=3 M P a$. The values of $\alpha, v_{r e f}$ and $v_{u}$ corresponding to this value of particle strength are 329 found to be $0.58,4.434$ and 0.069 , respectively.

330 Based on these values, the critical work is $W_{\text {crit }}=0.24 M P a$. It is also possible to define a value 331 of the work $W_{u}$, associated with the stabilisation of breakage, and indicating the start of the third 332 stage of the tri-segmented behavior:

$$
W_{u}=W_{c r i t}\left(\frac{v_{u}}{v_{i}}\right)^{-\frac{1}{\alpha}}
$$

333 which yields a value of $W_{u}=12.71 \mathrm{MPa}$.

334 Figure 13 is a plot of the two triaxial tests in the $\left(\log (v), \log \left(\frac{W}{V}\right)\right)$ space reported by Marsal 335 (1967) and compared to the proposed model (solid line). The first point corresponds to the initial $336 v_{i}=0.69$ at the reference work $\frac{W_{r e f}}{V}=0.01 \mathrm{MPa}$, which represents to the initial GSD. Test 1 is 337 a drained triaxial test with a confining stress of $\sigma_{3}=0.5 \mathrm{MPa}$. At the end of the test, the shear 338 stress reached a value of $\sigma_{1}-\sigma_{3}=1.6 \mathrm{MPa}$, and the volumetric strain was $\varepsilon_{v}=3 \%$ (dilation).

339 This test did not cause considerable change in the GSD, which is clear from the unchanged value 340 of $v$. Test 2 is a triaxial test conducted on a similar initial GSD as test 1 , and with a confining 341 stress of $\sigma_{3}=2.14 \mathrm{MPa}$. The shear stress developed by the end of this test was $\sigma_{1}-\sigma_{3}=$ $3425.4 \mathrm{MPa}$, which led to higher work development, and resulted in particle crushing. The model 343 was able to represent the difference between the two tests: the first test did not develop enough 344 work to cause particle breakage, while the second test went beyond the critical work, hence 345 developing breakage. It is important to note that none of the two tests came close to the 346 stabilisation work, which means that the material had an even bigger breakage potential. To reach 347 the final state where the GSD is self-similar, an additional $12 \mathrm{MPa}$ of applied mechanical work 348 was needed by the system.

\section{Influence of initial GSD on particle breakage}


350 The influence of the strength of the particles plays a significant role in defining the behavior of 351 the granular material with respect to breakage under loading. The multiscale approach adopted by 352 this model is representative of the effects of the grain on the behavior of the packing. On the one 353 hand, a grain specific parameter, chosen to be the tensile strength of a representative particle $d_{50}$, 354 is related to the three parameters of the model $\alpha, v_{r e f}$ and $v_{u}$. This means that the initiation, the 355 development and the stabilisation of breakage are all dependent on the particle strength. On the 356 other hand, the initial grain size distribution is taken into account through the parameter $v_{i}$, which 357 constitutes a measure of the potential of breakage available in the system, and when coupled with 358 the other parameters, is a key factor influencing the behavior of the system.

359 Tests conducted on Ottawa sand where the behavior of two granular distributions of the same 360 material was compared can be used to illustrate the importance of the initial grain size distribution 361 on the amount of breakage. The parameters of Ottawa are the following:

$$
\begin{gathered}
d_{50}=0.7 \mathrm{~mm} ; \bar{\sigma}_{t}=120 \mathrm{MPa} \\
\alpha=0.35 ; v_{r e f}=12.04 ; v_{u}=0.77
\end{gathered}
$$

362 The value for the $\overline{\sigma_{t}}$ was interpolated from figure 2 . The results of one oedometric test (Hagerty et 363 al. 1993), and two oedometric tests (Roberts and de Souza 1958) were analysed. The initial GSD 364 of the test by Hagerty et al. was $v_{i}=5.12$, while the initial GSDs for the tests by Roberts and de 365 Souza were $v_{i 1}=3.38$ and $v_{i 2}=1.59$, respectively. For all the tests, the GSDs were measured 366 at different stages of the loading, which explains the number of data points plotted in figure 14.

367 Let us compare the behavior of the two tests by Roberts and de Souza. The initial parameter $v_{i_{2}}$ 368 associated with the well-graded packing is smaller than $v_{i_{1}}$ which is associated with the uniformly 369 graded material. From figure 14, it is clear that the initiation of breakage occurs at a lower value 370 of $W / V$ for uniform Ottawa sand $\left(W_{\text {crit }} / V=0.1 \mathrm{MPa}\right.$ ) compared to $W_{\text {crit }} / V=2.2 \mathrm{MPa}$ for 371 well-graded Ottawa sand. This can be explained from a grain level point of view, where breakage 
372 is controlled by two competing parameters: the strength of the grain and the coordination number

373 (McDowell and Bolton 1998). Since this model does not account for the changes in strength 374 associated with the decrease in grain size that accompanies grain breakage, the effect of the 375 coordination number can be used to explain the difference in the critical work for the initiation of 376 crushing. In a well graded material, the bigger and weaker grains are 'shielded' by the smaller 377 and stronger grains. This configuration is the least favorable for the development of breakage, and 378 explains the delayed initiation of breakage. The uniform material is made of grains with 379 comparable sizes and strengths. The coordination number is usually small in this type of 380 distribution, which causes the grain to be in contact with a smaller number of other grains. This 381 mechanical configuration increases the chance of fracture compared with a grain with a higher 382 coordination number. After the initiation of breakage, the two granular distributions behave in the 383 same way, which is consistent with experimental observations.

384 The data reported above demonstrates also that the proposed model is able to consider adequately 385 the experiments from different authors on the same material under different conditions, since both 386 sets of results follow a unique breakage constitutive equation. This goes to show that the 387 parameters $\alpha$ and $v_{\text {ref }}$ are characteristic to the material, and are independent of the initial 388 distribution $v_{i}$.

\section{Influence of particle strength}

390 It is also important to analyse the effect of the particle strength on the development of breakage.

391 Figure 15 shows the evolution of the GSDs of different materials with different particle strengths

392 but with the same initial distribution and under identical loading conditions (Lo and Roy 1973).

393 As anticipated, the higher the particle strength, the less breakage for the same amount of input

394 work per unit volume. For the weaker particle, i.e. limestone, the final value of $v$ is 0.25 , that of 395 quartz is 0.41 while for the stronger $\mathrm{Al}_{2} \mathrm{O}_{3}$ it is 1.03 . 
396 The particle strength can be affected by its size or its mineralogy. If we compare the parameters $397 \alpha, v_{r e f}$ and $v_{u}$ for two materials with different particle strengths, the stronger material will have a

398 higher $v_{\text {ref }}$, a lower $\alpha$ and a higher $v_{u}$ (figure 16). If we take the example of a rockfill, where the 399 particles are weaker due to their important size, the smaller $v_{\text {ref }}$ and the higher $\alpha$ causes cracking 400 to develop early and more rapidly. The parameter $v_{u}$ is also smaller for these type of granular 401 media. In contrast, a laboratory sand (usually siliceous) will have a much higher particle strength 402 than the rockfill, which has the opposite effect of delaying the development of crushing, and 403 decreasing the rate of development of the process.

\section{Conclusions}

405 In this paper, a simple model was proposed with the aim of predicting the evolution of particle 406 breakage based on the mechanical conditions, the initial gradation, and the strength of the grain. 407 A breaking parameter representative of the grain size distribution (GSD) related to the mechanical 408 work per unit volume allows to predict the evolution of GSD during any loading condition.

409 The proposed conceptual model is representative of many aspects of the soil's behavior that are 410 usually ignored by the existing breakage models. For example, the grain strength plays a 411 determining role in controlling the parameters of the proposed model. The initial gradation is also 412 very important for estimating the critical mechanical state where breakage initiates. The 413 stabilisation of the particle breakage is also considered using the fractal fragmentation theory, and 414 relationships are established between the fractal dimension, the ultimate parameter $v_{u}$ and the 415 strength of the particles.

416 This model was essentially developed for engineering applications. By its use of common 417 parameters and techniques, it differentiates itself from the existing models. Using the mechanical 418 properties and the stress-strain curves of the soil, the user is able to correctly estimate the extent 419 of breakage in the soil, thus controlling its effects on the structure. This model can also be 
420 integrated into a complete constitutive model. One way to do it would be to introduce the tri421 linear behavior as a work hardening function.

\section{Acknowledgements}

423 This research is being funded by the Natural Sciences and Engineering Research Council of 424 Canada (NSERC) under a CRD Project Grant No. 470297-14 and Hydro Québec. The senior 425 author would like to mention the invaluable data provided by late Professor Marius Roy and 426 inspiring discussions on grain breakage while he was a young professor at Université Laval. The 427 authors are grateful to François Gilbert for his laboratory work on particle strength.

\section{References}

Atkinson, B.K. 1987. Fracture mechanics of rock. In Academic Press geology series. Elsevier. doi:10.1007/978-94-007-2595-9.

Biarez, J., and Hicher, P.-Y. 1994. Elementary Mechanics of Soil Behaviour: Saturated Remoulded Soils. Balkema, Rotterdam.

Billam, J. 1971. Some aspects of the behaviour of granular materials at high pressures. In Proceedings of the Roscoe memorial symposium. Edited by R.H.G. Parry. Cambridge. pp. 69-80.

Cavarretta, I. 2009. The influence of particle chararcteristics on the engineering behavior of granular materials. $\mathrm{PhD}$ thesis from Imperial College London, UK.

Colliat-Dangus, J.-L. 1986. Comportement des matériaux granulaires sous fortes contraintes Influence de la nature minéralogique du matériau étudié. $\mathrm{PhD}$ Thesis from l'université scientifique et médicale et l'institut national polytechnique de Grenoble, France.

Colliat-Dangus, J.-L., Desrues, J., and Foray, P. 1988. Triaxial Testing of Granular Soil Under 
Elevated Cell Pressure. In Advanced triaxial testing of soil and rock. ASTM, Philadephia, PA. pp. 290-310. doi:10.1520/STP29082S.

Coop, M.R., Sorensen, K.K., Bodas Freitas, T., and Georgoutsos, G. 2004. Particle breakage during shearing of a carbonate sand. Géotechnique, 54(3): 157-163. doi:10.1680/geot.2004.54.3.157.

Daouadji, A., Hicher, P.-Y., and Rahma, A. 2001. An elastoplastic model for granular materials taking into account grain breakage. European Journal of Mechanics - A/Solids, 20(1): 113137. doi:10.1016/S0997-7538(00)01130-X.

Einav, I. 2007a. Breakage mechanics-Part II: Modelling granular materials. Journal of the Mechanics and Physics of Solids, 55(6): 1298-1320. doi:10.1016/j.jmps.2006.11.004.

Einav, I. 2007b. Breakage mechanics-Part I: Theory. Journal of the Mechanics and Physics of Solids, 55(6): 1274-1297. doi:10.1016/j.jmps.2006.11.003.

Hagerty, M.M., Hite, D.R., Ullrich, C.R., and Hagerty, D.J. 1993. One-Dimensional HighPressure Compression of Granular Media. Journal of Geotechnical Engineering, 119(1): 118. doi:10.1061/(ASCE)0733-9410(1993)119:1(1).

Hardin, B.O. 1985. Crushing of Soil Particles. Journal of Geotechnical and Geoenvironmental Engineering, 10: 1177-1192. doi:10.1061/(ASCE)0733-9410(1985)111:10(1177).

Hu, W., Yin, Z., Dano, C., and Hicher, P.-Y. 2011. A constitutive model for granular materials considering grain breakage. Science China Technological Sciences, 54(8): 2188-2196. doi:10.1007/s11431-011-4491-0.

Jaeger, J.C. 1967. Failure of Rocks Under Tensile Conditions. International Journal of Rock Mechanics and Mining Sciences, 4: 219-227. doi:10.1016/0148-9062(67)90046-0.

Kikumoto, M., Wood, D.M., and Russell, A. 2010. Particle Crushing and Deformation 
Behaviour. Soils and Foundations, 50(4): 547-563. doi:10.3208/sandf.50.547.

Lade, P. V., Yamamuro, J.A., and Bopp, P.A. 1996. Significance of Particle Crushing in Granular Materials. American Society of Civil Engineers. doi:10.1061/(ASCE)07339410(1996)122:4(309).

Leclerc, I. 1998. Indice de broyage de matériaux pulvérulents en conditions oedométriques. $\mathrm{PhD}$ thesis from Laval University, Canada.

Lee, I.K. 1991. Mechanical behaviour of compacted decomposed granite soil. PhD thesis from City University London, UK.

Lee, K.L., and Farhoomand, I. 1967. Compressibility And Crushing Of Granular Soil In Anisotropic Triaxial Compression. Canadian Geotechnical Journal, 4(1): 68-86. doi:10.1139/t67-012.

Lo, K.Y., and Roy, M. 1973. Response of particulate materials at high pressures. Soils and Foundations, 13(1): 61-76. doi: 10.3208/sandf1972.13.61.

Marsal, R.J. 1967. Large-scale testing of rockfill materials. Journal of the Soil Mechanics and Foundations Division, 93(2), 27-43.

Marsal, R.J. 1973. Mechanical properties of rockfill. In Embankment Dam Engineering. Edited by R. Hirschfeld and S.J Poulos. Wiley, NY. pp. 109-200.

McDowell, G.R., and Amon, A. 2000. The application of Weibull statistics to the fracture of soil particles. Soils and foundations, 40(5): 133-141. doi:10.3208/sandf.40.5_133.

McDowell, G.R., and Bolton, M.D. 1998. On the micromechanics of crushable aggregates. Geotechnique, 48(5): 667-679. doi:10.1680/geot.1998.48.5.667.

McDowell, G.R., Nakata, Y., and Hyodo, M. 2002. On the plastic hardening of sand. 
Géotechnique, 52(5): 349-358. doi:10.1680/geot.2002.52.5.349.

Miura, N., and O-Hara, S. 1979. Particle-crushing of a decomposed granite soil under shear stresses. Soils and Foundations, 19(3): 1-14. doi:10.3208/sandf1972.19.3_1.

Nakata, Y., Hyodo, M., Hyde, A.F.L., Kato, Y., and Murata, H. 2001. Microscopic Particle Crushing of Sand Subjected to High Pressure One-Dimensional Compression. Soils and Foundations, 41(1): 69-82. doi:10.3208/sandf.41.69.

Roberts, J.E., and de Souza, J.M. 1958. The compressibility of sands. In Proceedings of the ASTM No. 58.

Roy, M. 1970. The shear behaviour of granular materials under high pressures with particular reference to particle breakage. $\mathrm{PhD}$ thesis from Laval University, Canada.

Russell, A.R., and Khalili, N. 2002. Drained cavity expansion in sands exhibiting particle crushing. International Journal for Numerical and Analytical Methods in Geomechanics, 26(4): 323-340. doi:10.1002/nag.203.

Salami, Y., Dano, C., and Hicher, P.-Y. 2017. An experimental study on the influence of the coordination number on grain crushing. European Journal of Environmental and Civil Engineering,. doi:10.1080/19648189.2017.1285251.

Soga, K. 2005. Microscopic characterisation of soils. In The COE Workshop on evaluation of mechanical behavior of granular materials. Hokkaido University, Sapporo, Japan.

Turcotte, D.L. 1986. Fractals and fragmentation. Journal of Geophysical Research, 91(B2): 1921. doi:10.1029/JB091iB02p01921.

Turcotte, D.L. 1997. Fractals and chaos in geology and geophysics. Cambridge University Press.

Wood, D., Kikumoto, M., and Russell, A. 2009. Particle crushing and deformation behaviour. In 
Proceedings, Prediction and Simulation Methods for Geohazard Mitigation. Edited by Oka, F., Murakami, A., and Kikumoto, M. CRC Press/Balkema. pp 263-268.

Yamamuro, J., and Lade, P. 1993. Effects of strain rate on instability of granular soils. Geotechnical Testing Journal, 16(3): 304-313. doi:10.1520/GTJ10051J. 


\section{Notations}

The following symbols are used in this paper:

$\begin{aligned} C_{u} & =\text { Coefficient of uniformity } \\ C_{c} & =\text { Crushing coefficient } \\ D & =\text { Fractal dimension } \\ d ; d_{\%} & =\text { Particle size; The size corresponding to the } \% \text { passing by mass } \\ F(d) & =\text { The cumulative grain size distribution by mass } \\ p, q & =\text { The triaxial stress parameters } \\ W ; W_{c r i t} ; W_{u} & =\text { The applied mechanical work; The critical work; The ultimate work } \\ \alpha & =\text { The slope of the breakage development segment in the model } \\ v ; v_{i} ; v_{r e f} ; v_{u} & =\text { The slope of the GSD in the log-log space; initial; reference; ultimate values } \\ \overline{\sigma_{t}} & =\text { The tensile strength of a particle of size } d_{50}\end{aligned}$




\section{Figure captions}

Figure 1. Force-displacement curve for the granitic particles.

Figure 2. Tensile strengths for multiple rocks and mineral particles.

Figure 3. Definition of the new breakage parameter.

Figure 4. Evolution of the coefficient of uniformity $C_{u}$ as a function of the effective isotropic mean stress $p$.

Figure 5. Evolution of the coefficient of uniformity $C_{u}$ as a function of the total input work per unit volume.

Figure 6. Data for crushed limestone (Lo and Roy 1973) as a function of input work per unit volume.

Figure 7. (a) Conceptual Breakage Model for an assemblage of particles (b) Evolution of parameter $v$ between its initial and ultimate values.

Figure 8. Evolution of parameters $\alpha$ (a) and $v_{r e f}$ (b) as functions of the tensile strengths $\overline{\sigma_{t}}$ for a variety of minerals.

Figure 9. Mechanical tests on Hostun sand (after Colliat-Dangus (1986) and Colliat-Dangus et al. (1988)) : (a) isotropic compression, (b) oedometric tests and (c) triaxial shear paths (CID).

Figure 10. Evolution of the crushing coefficient for Hostun sand.

Figure 11. Comparison of Model predictions and experimental data for Hostun sand.

Figure 12. Evolution of $v_{u}$ as a function of the tensile strength $\overline{\sigma_{t}}$ for a variety of minerals.

Figure 13. Model Predictions for Marsal's (1967) granitic gneiss.

Figure 14. Effect of the initial grading on the onset of breakage for Ottawa sand. 
Figure 15. Final value of $v$ for different materials at the same initial grading with different particle strengths.

Figure 16. Effects of particle strength on the parameters of the proposed model. 


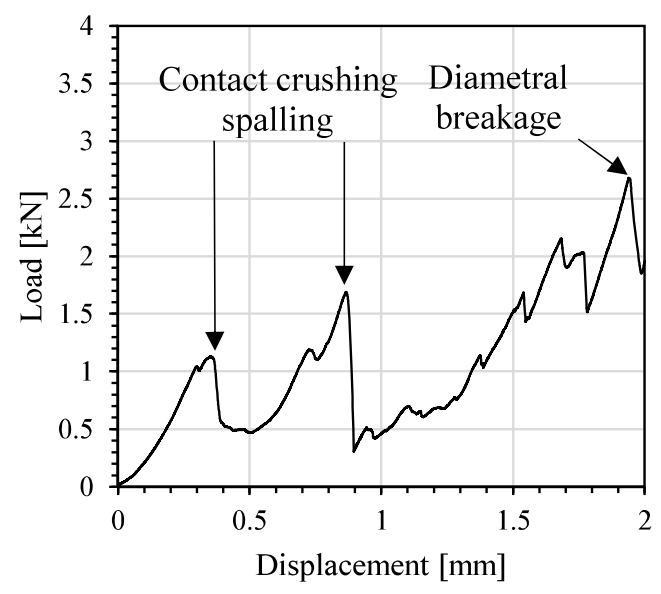

Figure 1. Force-displacement curve for the granitic particles. 


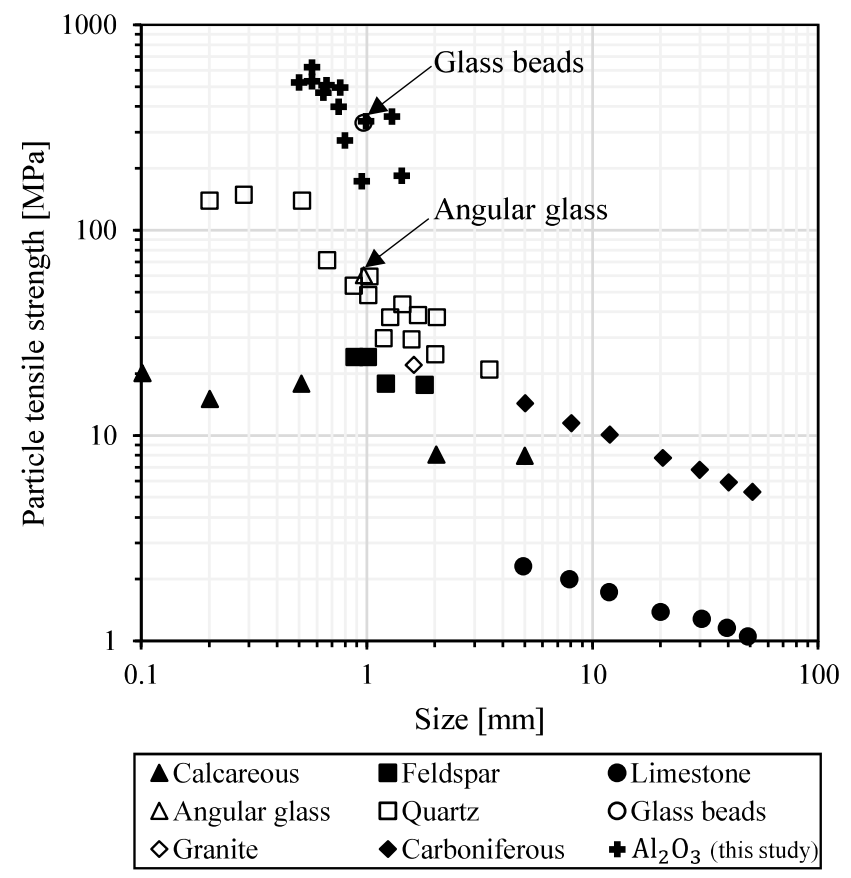

Figure 2. Tensile strengths for multiple rocks and mineral particles. 


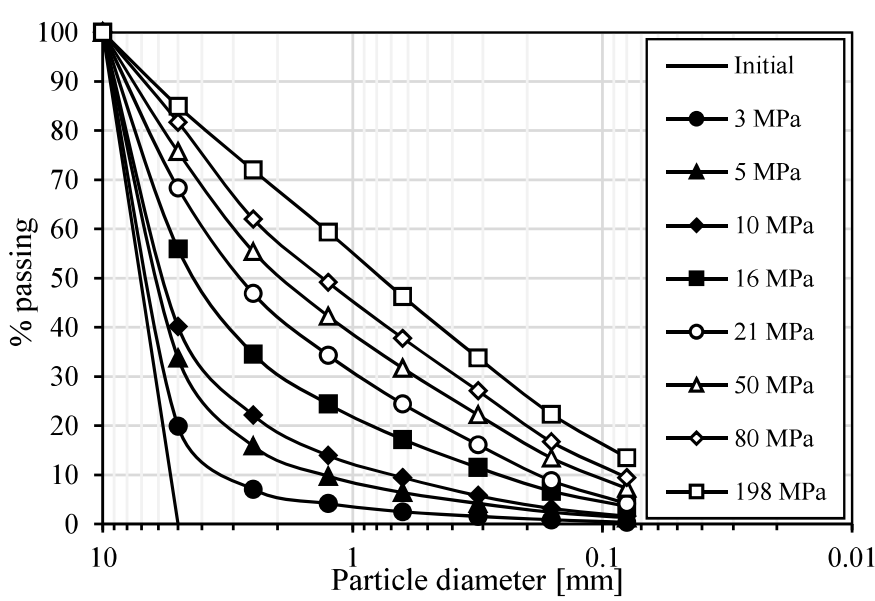

(a)

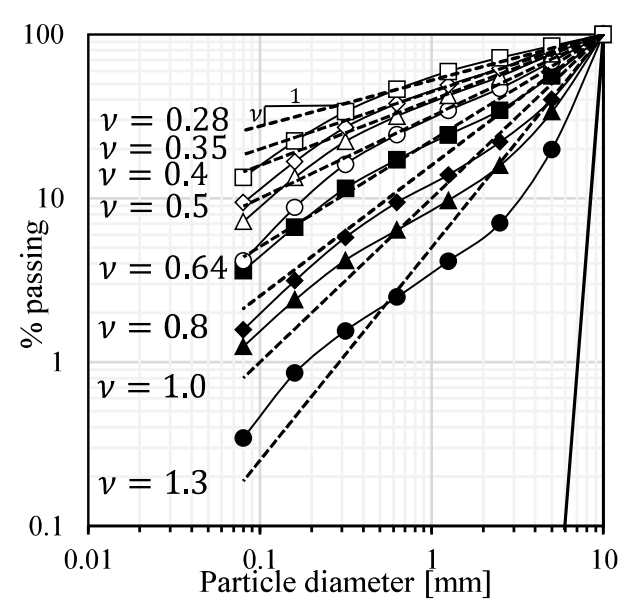

(b)

Figure 3. Definition of the new breakage parameter. 


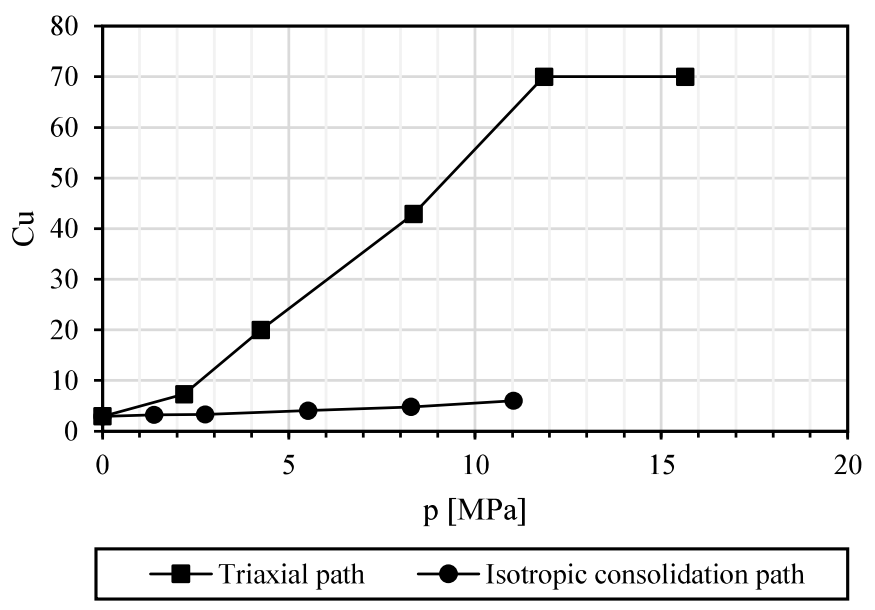

Figure 4. Evolution of the coefficient of uniformity $\mathrm{Cu}$ as a function of the effective isotropic mean stress $\mathrm{p}$. 


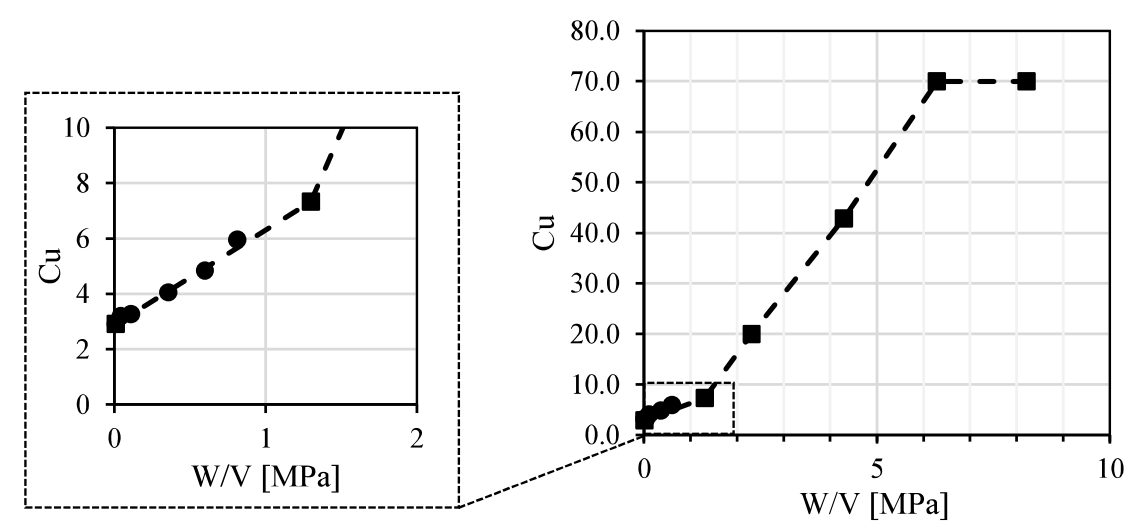

- Triaxial stress path

- Isotropic consolidation stress path

Figure 5. Evolution of the coefficient of uniformity $\mathrm{Cu}$ as a function of the total input work per unit volume. 


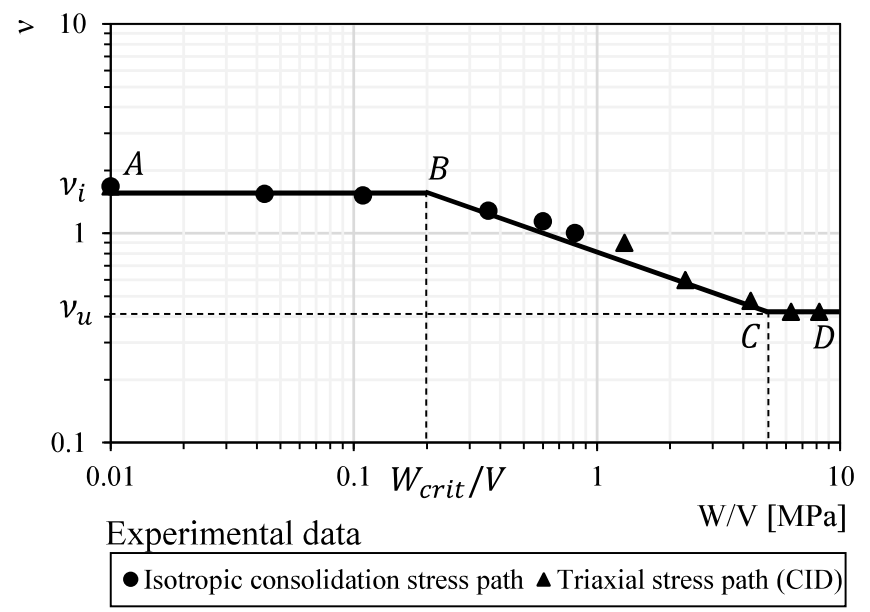

Figure 6. Data for crushed limestone (Lo and Roy, 1973) as a function of input work per unit volume. 


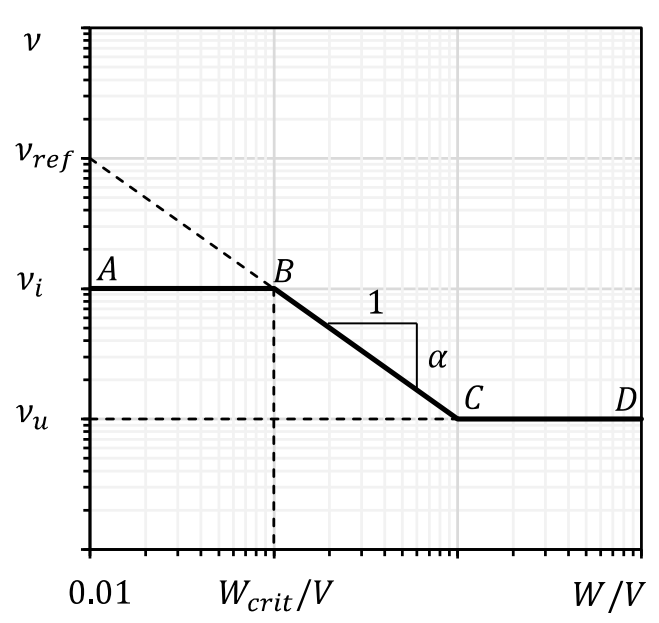

(a)

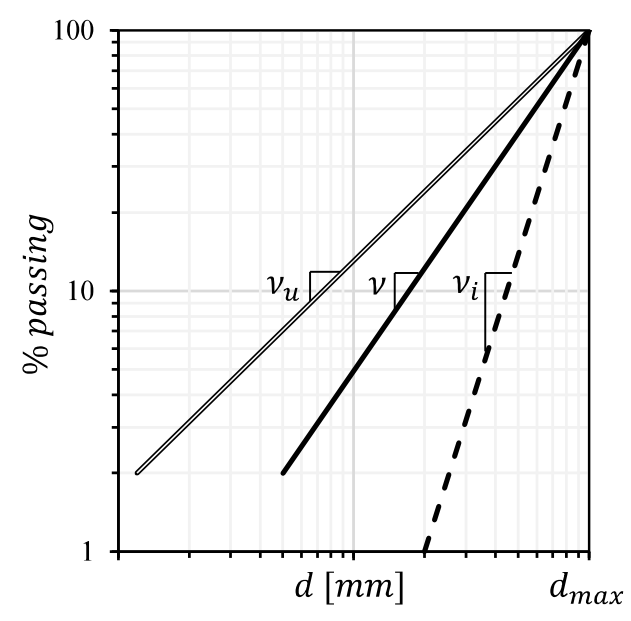

(b)

Figure 7. (a) Conceptual Breakage Model for an assemblage of particles (b) Evolution of parameter $v$ between its initial and ultimate values. 


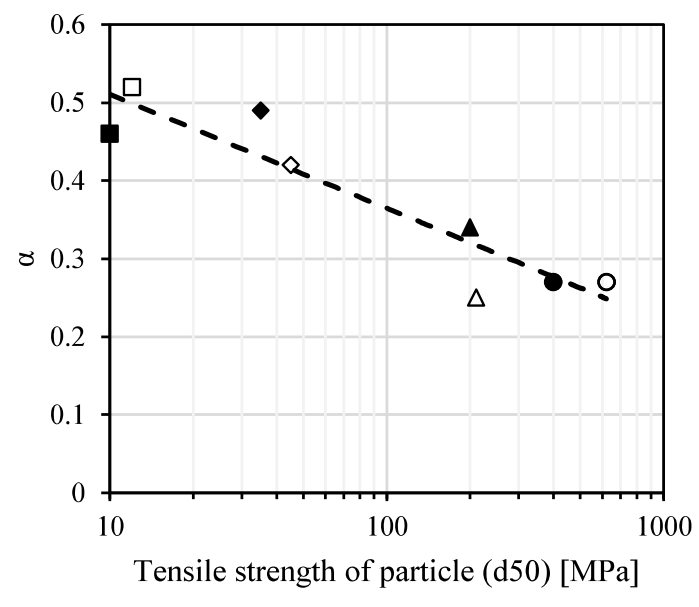

\begin{tabular}{|ll|}
\hline Romaine Granite & $\square$ Crushed Limestone \\
$\bullet$ Carbonate Sand & $\diamond$ Kenamu Sand \\
$\Delta$ Quartz & $\Delta$ Cambria Sand \\
Ottawa Sand & $\mathrm{OAl}_{2} \mathrm{O}_{3}$ Particles
\end{tabular}

(a)

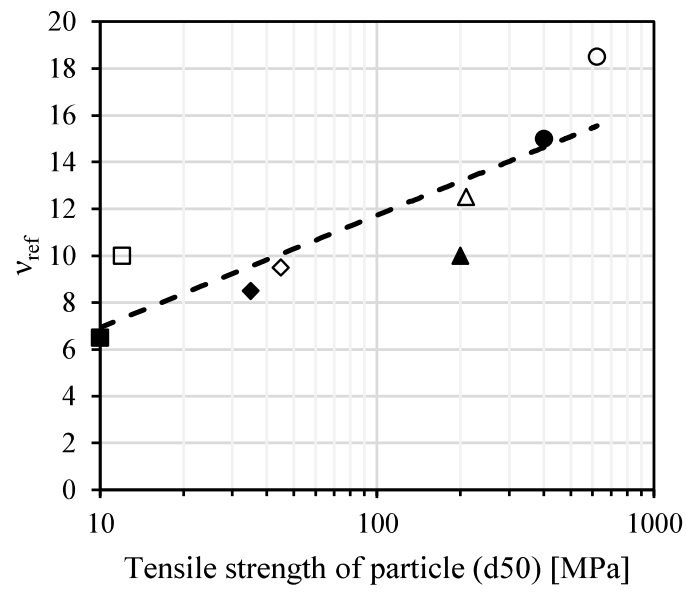

$\begin{array}{ll}\text { - Romaine Granite } & \square \text { Crushed Limestone } \\ \bullet \text { Carbonate Sand } & \diamond \text { Kenamu Sand } \\ \Delta \text { Quartz } & \Delta \text { Cambria Sand } \\ \text { - Ottawa Sand } & \mathrm{OAl}_{2} \mathrm{O}_{3} \text { Particles }\end{array}$

(b)

Figure 8. Evolution of parameters $\alpha$ (a) and vref (b) as functions of the tensile strengths $\bar{\sigma}$ t for a variety of minerals. 


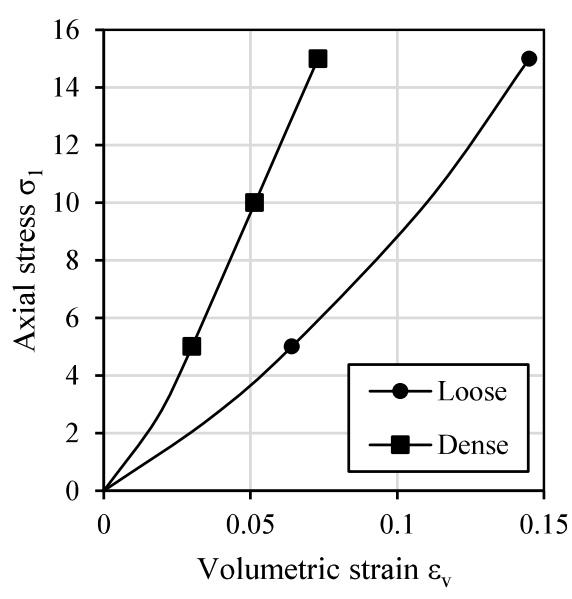

(a)

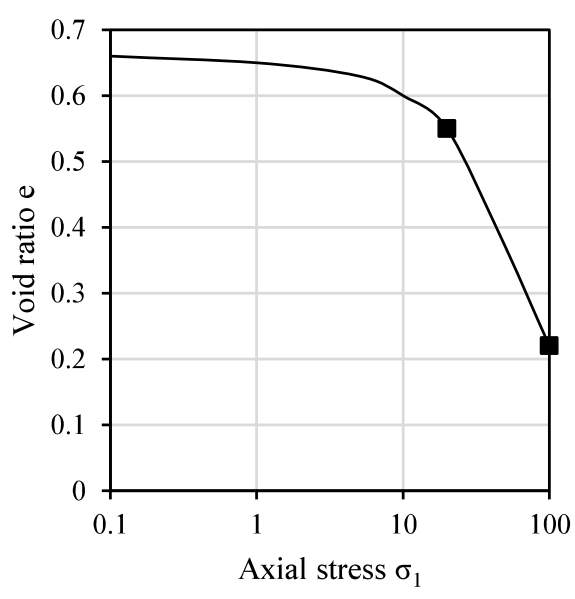

(b)

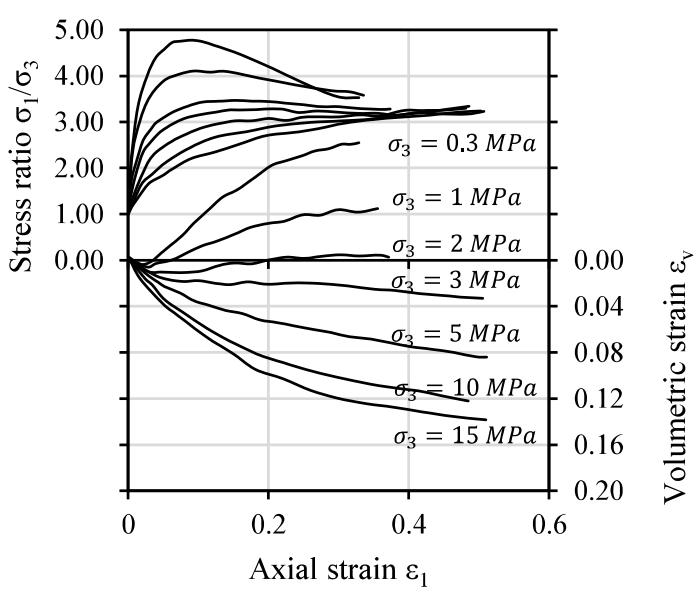

(c)

Figure 9. Mechanical tests on Hostun sand (after Colliat-Dangus (1986) and Colliat-Dangus et al. (1988)) : (a) isotropic compression, (b) oedometric tests and (c) triaxial shear paths (CID). 


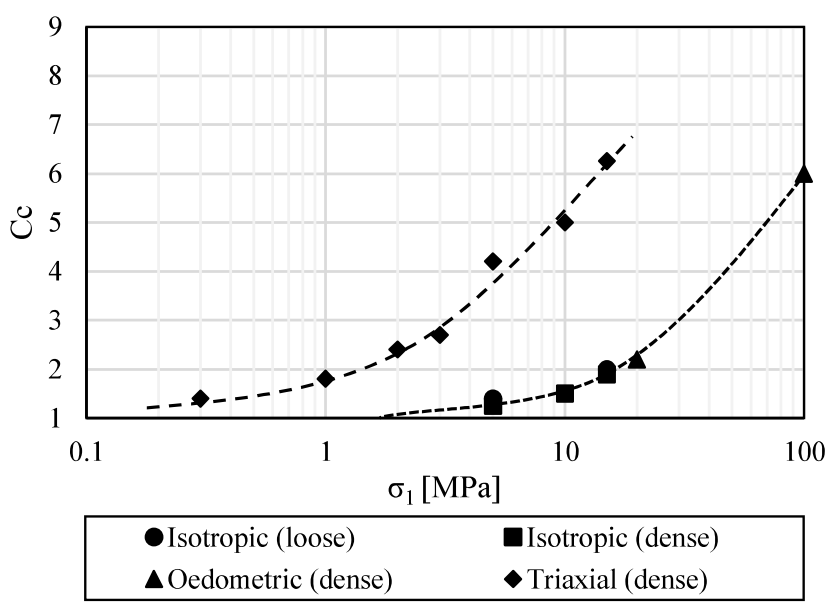

Figure 10. Evolution of the crushing coefficient for Hostun sand. 


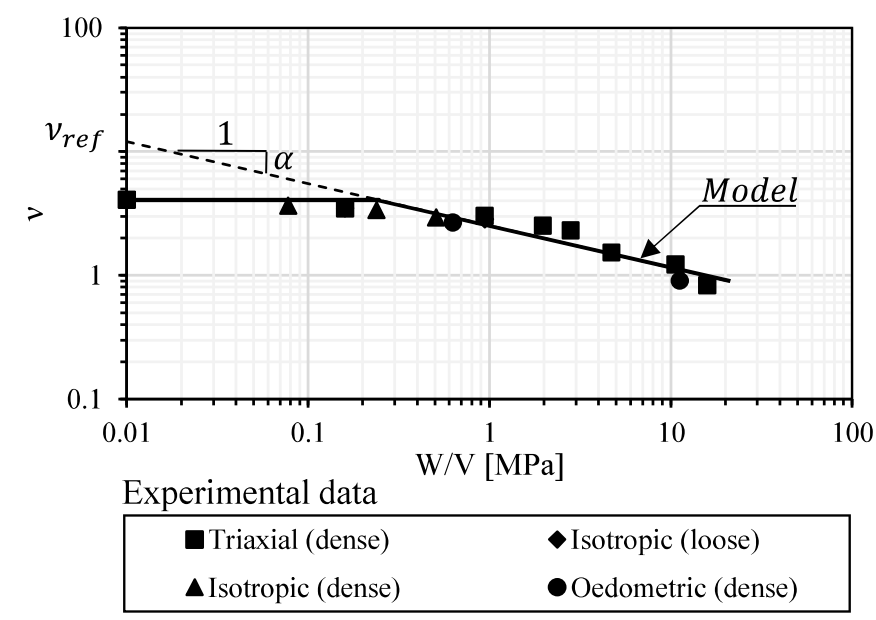

Figure 11. Comparison of Model predictions and experimental data for Hostun sand. 


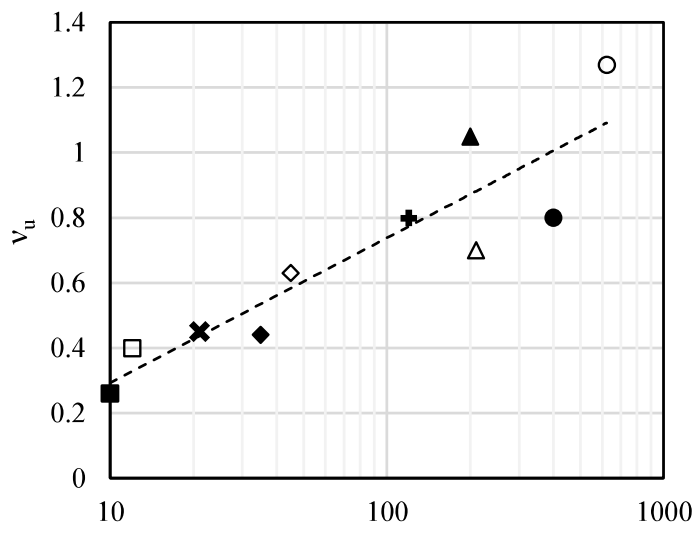

Tensile strength of particle (d50) $[\mathrm{MPa}]$

$\begin{array}{ll}\text { - Romaine Granite } & \square \text { Crushed Limestone } \\ \text { ×Calcacerous Sand } & \bullet \text { Carbonate Sand } \\ \diamond \text { Kenamu Sand } & \text { † Fine Hostun Sand } \\ \Delta \text { Quartz } & \Delta \text { Cambria Sand } \\ \text { - Ottawa Sand } & \mathrm{OAl}_{2} \mathrm{O}_{3} \text { particles }\end{array}$

Figure 12. Evolution of vu as a function of the tensile strength $\bar{\sigma}$ t for a variety of minerals. 


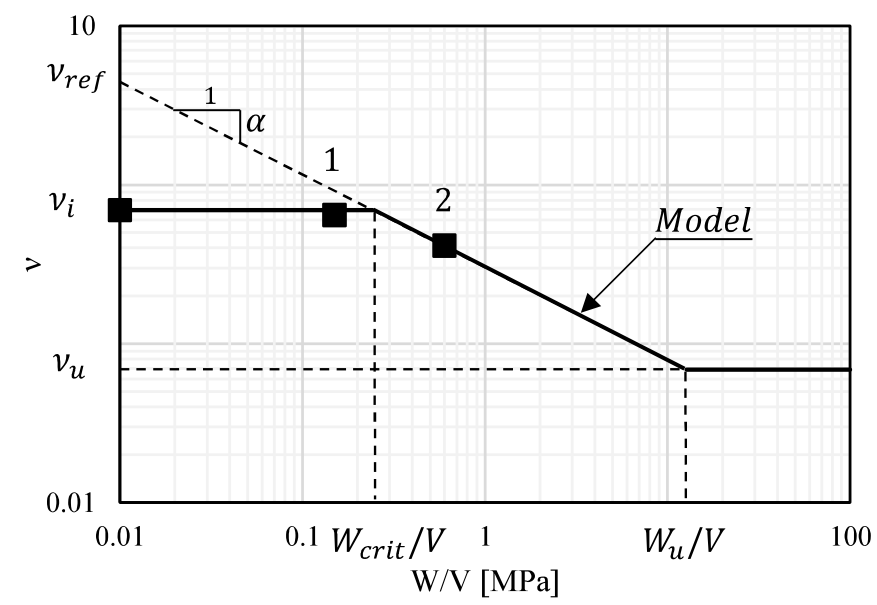

Figure 13. Model Predictions for Marsal's (1967) granitic gneiss. 


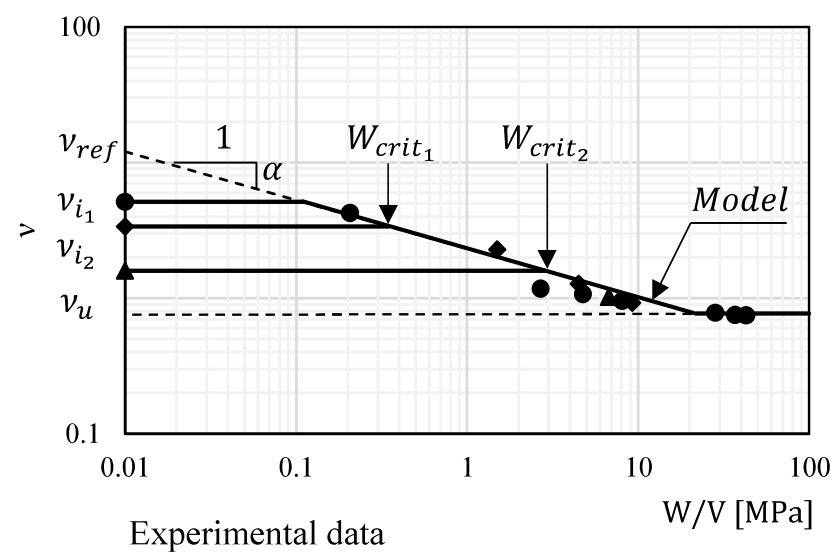

- Hagerty et al. (1993)

- Test 1, Roberts and de Souza (1958)

$\Delta$ Test 2, Roberts and de Souza (1958)

Figure 14. Effect of the initial grading on the onset of breakage for Ottawa sand. 


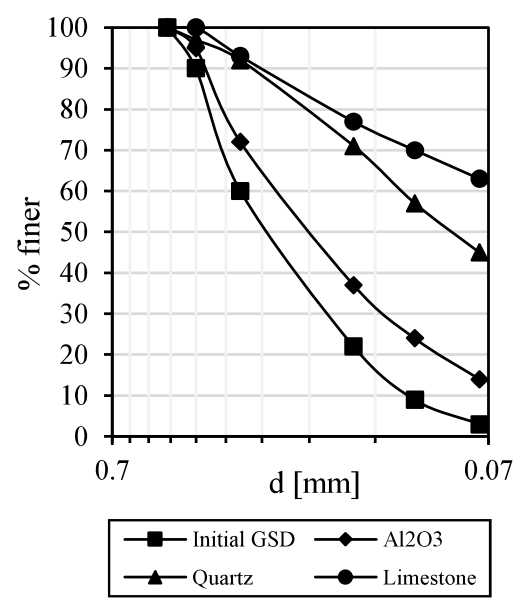

(a)

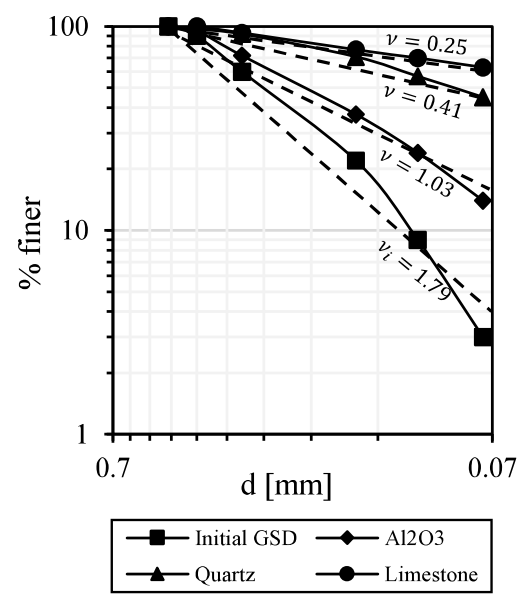

(b)

Figure 15. Final value of $v$ for different materials at the same initial grading with different particle strengths. 


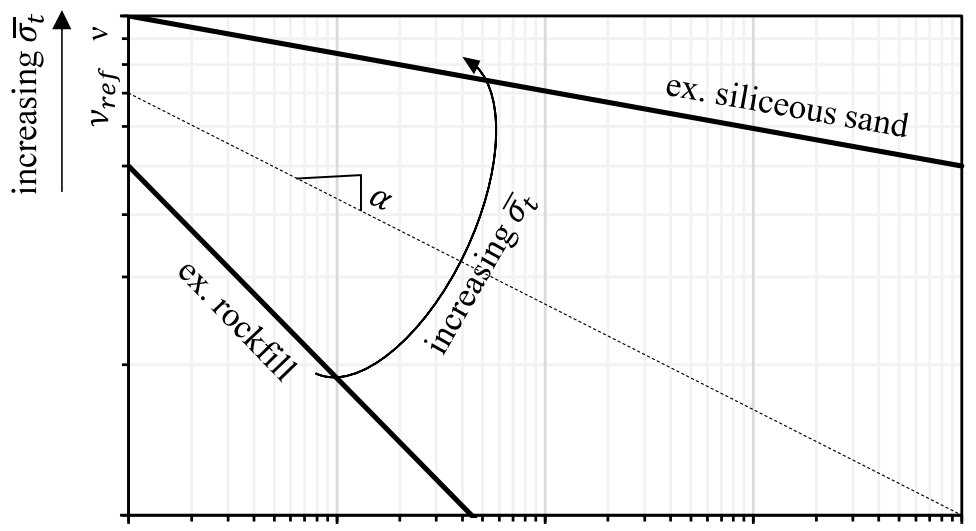

$\mathrm{W} / \mathrm{V}$

Figure 16. Effects of particle strength on the parameters of the proposed model. 